Revista Kinesis, Santa Maria v.35 n.1, 2017, Jan - abr , p. 71 - 84 ReVISTA KINESIS Centro de Educação Física e Desporto - UFSM

DOI 10.5902/2316546423291

Data de submissão 30-07-2016

Data de Aceite: 12-01-2017

\title{
ATLETAS BRASILEIROS NOS JOGOS PARAPAN-AMERICANOS DE 2015: UMA ABORDAGEM APELATIVA DO SITE GLOBOESPORTE.COM
}

\author{
Brazilian athletes in the Parapan American Games of 2015: an appealing approach to \\ the website Globoesporte.com
}

Deportistas brasileños en los Juegos Parapanamericanos de 2015: un enfoque atractivo de los temas periodísticos en la web Globoesporte.com

\author{
Kassieli Joaquina Gonçalves de Mello dos Santos \\ kassigmello@gmail.com \\ Universidade Federal do Rio Grande do Sul \\ Janice Zarpellon Mazo \\ janice.mazo@ufrgs.br \\ Universidade Federal do Rio Grande do Sul \\ Eduardo Klein Carmona \\ eduardok.carmona@hotmail.com \\ Universidade Federal do Rio Grande do Sul
}

\begin{abstract}
Resumo
O presente estudo tem como objetivo investigar como foram exibidos os atletas que representaram o Brasil nos Jogos Parapan-Americanos de 2015, em Toronto, Canadá, pelo site de notícias Globoesporte.com. Verificou-se, na produção jornalística esportiva, a abordagem e a terminologia adotadas para informar o desempenho dos atletas medalhistas. Realizou-se a análise documental das matérias jornalísticas selecionadas, de acordo com a abordagem apelativa. O estudo revela a representação estereotipada conferida pela mídia esportiva aos atletas, destacando-se as suas limitações, como personagens de histórias de superação.
\end{abstract}

Palavras-Chave: Jogos Parapan-Americanos; Atleta com deficiência; Cobertura jornalística, Atletas paralímpicos.

\section{ABSTRACT}

This paper aims to investigate the representations of athletes who participated in the 2015 Parapan American Games, in Toronto, Canada, published at Globoesporte.com news website. The approach and the terminology adopted to report the performance of medalist athletes were verified in the sports journalistic production. The documental analysis of the journalistic articles selected is presented according to the appealing approach. The study reveals a stereotypical representation given by the sports media to athletes, highlighting their limitations, as characters in overcoming stories.

Keywords: Parapan American Games; Disabled athletes; Journalistic coverage; Paralympic athlete.

\section{Resumen}

El presente estudio tiene como objetivo investigar las representaciones culturales vehiculadas en el sitio de noticias Globoesporte.com acerca de los atletas participantes de los Juegos Parapan-Americanos de 2015 en la ciudad de Toronto, Canadá. Se ha verificado en la producción periodística deportiva cual fue el abordaje y la terminología adoptada para hacer los informes acerca del desempeño de los atletas vencedores. Ha sido realizado el análisis documental de las materias periodísticas seleccionadas de acuerdo con su abordaje apelativo. El estudio ha revelado la representación estereotipada que los mediáticos deportivos agregan al imagen de los atletas, destacando sus limitaciones y exhibiéndolos como personajes de historias de superación. 


\section{Introdução}

Os meios de comunicação possuem um importante papel na sociedade no processo de produção das notícias. "Os jornalistas são participantes ativos na definição e na construção das notícias, e, por consequência, na construção da realidade" (TRAQUINA, 2005, p. 26). A mídia cumpre seu papel em informar, com notícias de interesse social, influenciando sobre a percepção do público e sua construção de sentidos. Segundo Curado (2002, p. 16), além de a notícia revelar como se sucederam determinados fatos e os personagens envolvidos nos acontecimentos, também "localiza geograficamente onde ocorreram ou ainda estão acontecendo, descreve as suas circunstâncias, e os situa, num contexto histórico para dar-lhes perspectiva e noção da sua amplitude e dos seus significados".

Com a difusão da informação e o relevante papel social conquistado pelo fenômeno esportivo, o jornalismo expandiu suas áreas de atuação e se particularizou, sendo uma das especializações o jornalismo esportivo. $O$ esporte de alto rendimento foi visto como uma área lucrativa e teve definido seu lugar de destaque nos meios de comunicação. As práticas esportivas foram apropriadas por diferentes grupos sociais, inclusive pelas pessoas com deficiência, que também se inseriram no esporte de alto rendimento: o esporte paralímpico.

O estudo tem como objetivo investigar como foram exibidos os atletas que representaram o Brasil nos Jogos Parapan-Americanos de 2015, em Toronto, Canadá, pelo site de notícias Globoesporte. com. Ao passo que, também, busca questionar a visibilidade conferida aos Jogos Parapan-Americanos de 2015.

A pesquisa foi realizada por meio da análise documental das matérias jornalísticas veiculadas pelo site de notícias Globoesporte.com. O meio de comunicação escolhido para análise caracteriza-se pela veiculação de jornalismo esportivo ao informar e entreter com notícias sobre o mundo dos esportes. Devido à consolidação da Era Digital, o site foi lançado em 2005 chamado inicialmente como "Esporte na Globo" e no ano seguinte adotou-se o nome atual. Tal veículo de informação foi criado a partir da convergência entre os programas esportivos do Grupo Globo: Globo Esporte, Auto Esporte, Esporte Espetacular.

No período em que ocorreram os Jogos Parapan-Americanos, de sete a 15 de agosto de 2015, foram veiculadas 90 matérias sobre o evento esportivo, na editoria Parapan do site Globoesporte.com. Deste total, para o estudo, elegeram-se nove matérias veiculadas na editoria do site, as quais foram identificadas por meio dos títulos e fotografias, a partir do critério da abordagem apelativa (SEIXAS, 2013). As nove matérias escolhidas aludiam cada uma delas a um dia da semana e deveriam evidenciar a exploração da condição de pessoa com deficiência física como representação de superação ou como vítima de fatalidade, cunhando o uso de estereótipos ao retratar os atletas na competição. 
Conforme Alexandre (2001, p. 123): "a mídia, integrada por um grupo de especialistas formadores e, sobretudo difusores de representações sociais, é responsável pela estruturação de sistemas de comunicação que visam comunicar, difundir ou propagar determinadas representações". Nesta perspectiva, buscou-se verificar como os atletas são expostos pela mídia, com particular ênfase na terminologia utilizada, a qual possibilita a evidência empírica de suporte para as demais conjecturas de investigação.

Nesta direção, espera-se contribuir para a reflexão sobre a produção jornalística esportiva, que, por vezes, torna-se disseminadora de estigmas e posturas preconceituosas transmitidas culturalmente. Tais informações podem dificultar o reconhecimento do esporte praticado por atletas com deficiência, sua propagação e desenvolvimento social, tornando-o conhecido de forma estereotipada.

\section{JOGOS PARAPAN-AMERICANOS}

A primeira edição oficial dos Jogos Parapan-Americanos ocorreu em 1999, na cidade do México (México), com a característica de evento de qualificação para os Jogos Paralímpicos. Na época participaram cerca de 1.000 atletas de 18 países em competições de quatro modalidades esportivas. A segunda edição dos Jogos Parapan-Americanos, em 2003, foi realizada em Mar del Plata, Argentina. Com o êxito já da primeira edição do evento, desta vez, estiveram presentes aproximadamente 1.500 atletas oriundos de 28 países, competindo em nove modalidades esportivas (SANTOS, 2015).

Os Jogos Parapan-Americanos de 2007, na cidade do Rio de Janeiro representam um marco na história deste evento, pois foram disputados nas mesmas instalações dos Jogos Pan-Americanos. Além disso, um total de 1.150 atletas competiu nas 10 modalidades esportivas do evento. Cabe destacar que as instalações da Vila Pan-Americana foram projetadas para, também, atender os atletas com deficiências, sendo os Jogos Panamericanos e os Jogos Parapan-Americanos organizados pelo mesmo comitê organizador.

Em 2011, nos Jogos Parapan-Americanos de Guadalajara, México, cerca de 1.300 atletas, de 26 países, participou do evento esportivo, em 13 modalidades diferentes, sendo utilizadas as mesmas instalações dos Jogos Pan-Americanos. Na quinta edição do evento, em 2015, os Jogos Parapan-Americanos foram sediados em Toronto, Canadá, contando com 1.500 atletas de 28 países, competindo em 15 modalidades esportivas; este foi o maior número de modalidades em todas as edições do evento (SANTOS, 2015).

Diante do cenário descrito acima, cabe destacar que tais dados revelam haver o desenvolvimento progressivo do evento pan-americano destinado às pessoas com deficiência desde sua primeira edição. Com o decorrer dos anos, os Jogos Parapan-Americanos ganharam popularidade e certo espaço no âmbito esportivo e entre os meios de comunicação. Embora, a integração e reabilitação foram expostas em determinado momento como os principais motivos para a inserção dos deficientes nos esportes, a prática do esporte de alto rendimento distinguiu uma nova percepção corporal sobre si mesmo no esporte.

Segundo Brazuna e Castro (2001), a nova identidade de atleta é o resultado mais importante para o atleta deficiente físico. A conquista do pódio, talvez, para o atleta com deficiência representa a vitória sobre si mesmo. Nesta direção, o jornalismo especializado parece veicular cada vez mais outras repre- 
sentações do atleta com deficiência.

No jornalismo, o resultado da cobertura jornalística e apuração das informações, é a veiculação da notícia, a qual é construída a partir de valores e critérios estabelecidos com base na objetividade e imparcialidade jornalística. O jornalismo esportivo caracteriza-se pela cobertura dos fatos relacionados ao esporte, por isso o profissional dessa área precisa explorar as diferentes modalidades esportivas, afim de que possa trazer notícias dos acontecimentos que permeiam este universo.

A expansão tecnológica proporcionou aos meios de comunicação ampliar a veiculação de notícias nas diferentes especialidades. O crescente número de atletas nas delegações que participam dos Jogos Paralímpicos, o aumento na venda de ingressos e inserção de novas modalidades a cada edição do evento esportivo, estimulam a disseminação do assunto por parte da mídia, que precisa atender a um novo público decorrente do crescimento de uma modalidade até então pouco explorada nos meios de comunicação. A veiculação das notícias abordando o esporte paralímpico impulsiona e legitima a modalidade esportiva como pauta jornalística.

\section{JORNALISMO ESPORTIVO}

Ao noticiar o esporte de alto rendimento praticado por atletas com deficiência, o jornalismo esportivo cumpre seu papel em informar sobre as diferentes modalidades esportivas, ampliando o conhecimento do público. Como jornalismo especializado, no entanto, é necessário repensar qual é o sentido da mensagem que se está difundindo. Tal comunicação precisa transmitir objetividade e credibilidade, informando de forma completa. Dessa forma, a veiculação na plataforma online permite ao jornalista produzir conteúdo mais aprofundado, através do uso de recursos multimídia, sem a geração de custos.

Alcoba (1980) destaca a necessidade de o jornalista especializar-se, para que possa escrever, falar e apresentar o jornalismo esportivo de uma forma especializada com uma linguagem própria, com qualidade, preparado para tratar das diferentes modalidades, sejam provenientes do esporte olímpico ou paralímpico. De acordo com Barbeiro e Rangel (2006, p. 34): “Isso não quer dizer que não se possa se especializar neste ou naquele esporte e conhecê-lo a fundo, o que, aliás, é desejável. Isso não livra ninguém de ter um conhecimento geral dos esportes mais populares. Os que não são conhecidos merecem ser estudados".

Na produção de uma matéria esportiva, o meio de comunicação especializado necessita ter conhecimento e habilidade para transmitir informações relevantes, construindo mensagens isentas de senso comum e estigmas. Erbolato (1981, p. 11-12) alerta os jornalistas: "Por mais competente e inteligente que seja não consegue bons resultados ao redigir sobre um assunto que ignora”. De tal modo que, o jornalista esportivo deve estar apto para informar na sua especialidade, ou seja, sobre as práticas esportivas, independente se são esportes olímpicos, esportes paralímpicos ou não fazem parte destes cenários.

No caso da prática esportiva por pessoas com deficiência, sua disseminação se estabelece como uma conquista social. O esporte por si só se comunica, já o jornalista tem a função de transformar em imagem, som e texto essa informação. Castro (1995, p. 56) afirma que "o esporte em si mesmo, é um veiculo de comunicação. Os esportistas, com suas atuações, “comunicam” alegria ou tristeza, força ou debilidade, vontade ou indecisão; enfim, muitos sentimentos que transmitem aos demais, com a plastici- 
dade de seus movimentos".

Estabelece-se a premissa de que o jornalista esportivo deve informar com conhecimento e de forma cuidadosa, para que não seja um disseminador de estereótipos e posturas preconceituosas. A abordagem utilizada na construção das mensagens é um aspecto que influencia diretamente na percepção do público e, para isso, o senso crítico é um importante aliado do jornalista. A mídia esportiva não deve ser uma disseminadora de mensagens apelativas que se aproveita dos sentimentos de comoção do público. Justamente, o papel do jornalista é transmitir a informação identificando personagens e localizando acontecimentos e contextos históricos em seus sentidos e significados.

\section{O ATLETA COM DEFICIÊNCIA NA COBERTURA JORNALÍSTICA}

A análise das características predominantes na cobertura jornalística realizada pelo site de notícias Globo Esporte nos Jogos Parapan-Americanos de 2015, revelou que os atletas são associados à imagem de superação. Os títulos e fotografias das matérias evidenciam a representação estereotipada acerca desses atletas que são representados como vítimas e heróis. Tal construção sociocultural deste sujeito histórico, talvez possa ser explicada pelos valores culturais que são estabelecidos pela sociedade e são utilizados para categorizar as pessoas que fogem aos padrões de normalização, aferindo a estas, determinados rótulos sociais (MARQUES, 2001).

As nove matérias do site foram escolhidas devido suas características que as identificam como apelativas (SEIXAS, 2015). Identificou-se a ocorrência de informação sobre os incidentes ocorridos com os atletas paralímpicos que geraram a deficiência, por exemplo. Através das fotografias que ilustram as matérias, se percebe a preocupação em evidenciar as limitações associadas à deficiência, como uma informação mais importante até mesmo que o desempenho do atleta e a própria prática esportiva. Hilgemberg e Novais (2009, p. 4) constataram a recorrência de tais características na mídia:

Os atletas com deficiência tendem a ser retratados como "vítimas" ou, em alternativa, como pessoas "corajosas" que "superaram" o próprio "sofrimento" da deficiência para participar em um evento esportivo. Este último estereótipo - o do super-herói - deixa a impressão de que a pessoa com deficiência para se ajustar terá de fazer algo extraordinário ou realizar um esforço heróico para compensar a sua limitação.

Hilgemberg (2014a) em seu estudo sobre a cobertura midiática dos Jogos Paralímpicos de 2012, em Londres, também evidenciou o discurso que enfatiza momentos de dificuldades relacionados à deficiência nas reportagens veiculadas na mídia especializada. A autora (2014a) discorda do discurso que enfatiza uma suposta tragédia na vida do atleta, o qual encontra no esporte um meio de superação do sofrimento. Considera a superação como uma característica do atleta, independente se tem ou não algum tipo de deficiência, a qual é capaz de transformá-lo em um herói. Todavia, no que diz respeito à atleta com deficiência, Hilgemberg (2014a, p. 12), pondera: "Contudo, no caso de atletas paralímpicos a superação é entendida como uma forma de compensação, e apenas o esforço para se tornar um paratleta é suficiente para que o mesmo seja louvado como herói”.

Com relação à mídia, no caso do atleta com deficiência, de um atleta paralímpico, o jornalista deve 
buscar representá-lo no evento esportivo paralímpico com o mesmo comprometimento com que realiza a cobertura jornalística dos atletas olímpicos, por exemplo, nos Jogos Olímpicos. Mesmo que o jornalista esportivo tenha o domínio sobre a área, conhecimento sobre os atletas, modalidades, regras e histórico da competição, o profissional precisa ter capacidade de transmitir tais informações com precisão. Camargo (2005, p. 9) alerta sobre o impacto dos meios de comunicação de massa. "Esta ação promove o crescimento do esporte enquanto espetáculo, proporcionado pela mídia especializada, que ao informar sobre o fato esportivo tem a necessidade de fazê-lo com qualidade".

Muitos veículos de comunicação se atêm a informações de senso comum sobre os atletas com deficiência, os quais são os personagens das matérias. A produção de tais reportagens carece de mais profundidade sobre as modalidades esportivas, acerca do histórico sobre o desempenho do atleta e outros fatores relacionados à prática esportiva. Neste caso, o leitor fica carente de uma narrativa mais densa, contextualizada e que dê significado a informação no cenário do esporte adaptado e paralímpico.

Um recurso que possibilita ao leitor familiarizar-se com este universo esportivo é a plataforma online, pois possui diversos recursos multimídia para tal veiculação, com a possibilidade de mostrar por meio da imagem e som a prática esportiva a que se reporta. Com relação às reportagens analisadas para fins deste estudo, apenas duas publicações referiram o recurso de vídeo. As demais utilizaram de três a seis fotografias, que, no entanto, não exploram o valor de transmissão da imagem para informar sobre a modalidade esportiva.

Em 2015, o Brasil contou com a maior delegação de sua história nos Jogos Para-Panamericanos, totalizando 272 atletas e mantendo a liderança no quadro de medalhas. Porém, os atletas brasileiros continuaram sendo enfocados sob o ponto de vista de suas limitações. O esporte adaptado na perspectiva do alto rendimento é associado fortemente às dificuldades superadas pelos atletas, ficando em segundo plano os fatores relacionados às performances dos mesmos. A análise das notícias evidenciou a construção de estereótipos dos atletas.

A notícia do site Globoesporte.com (REBELLO; GUERRA 07/08/2015a), com o título "Vovó? Aos 45 anos, Rosália coloca novatas no bolso e esbanja boa forma" destaca a habilidade de Rosália na cadeira de rodas, ressaltando sua boa condição física em relação às suas limitações motoras. A atleta é representada com a ideia de "super-humano". A fotografia principal da notícia mostra a atleta manuseando a cadeira de rodas, sem informação sobre a modalidade esportiva praticada pela atleta, o basquetebol em cadeira de rodas, como é possível perceber na identificação da imagem 1. A matéria evidencia a superação da atleta, ocasionando o questionamento sobre a pertinência da notícia em tal editoria.

Afinal, a imagem fotográfica, que é impregnada de simbolismo e conota interpretações, possui relevante papel no fazer jornalístico, tonificando a credibilidade perante os leitores, bem como a capacidade de transmissão de informação. Para Kossoy (1999) "existe sempre uma motivação interior ou exterior, pessoal ou profissional, para a criação de uma fotografia e aí reside a primeira opção do fotógrafo, quando este seleciona o assunto em função de determinada finalidade/intencionalidade” (p. 27). 


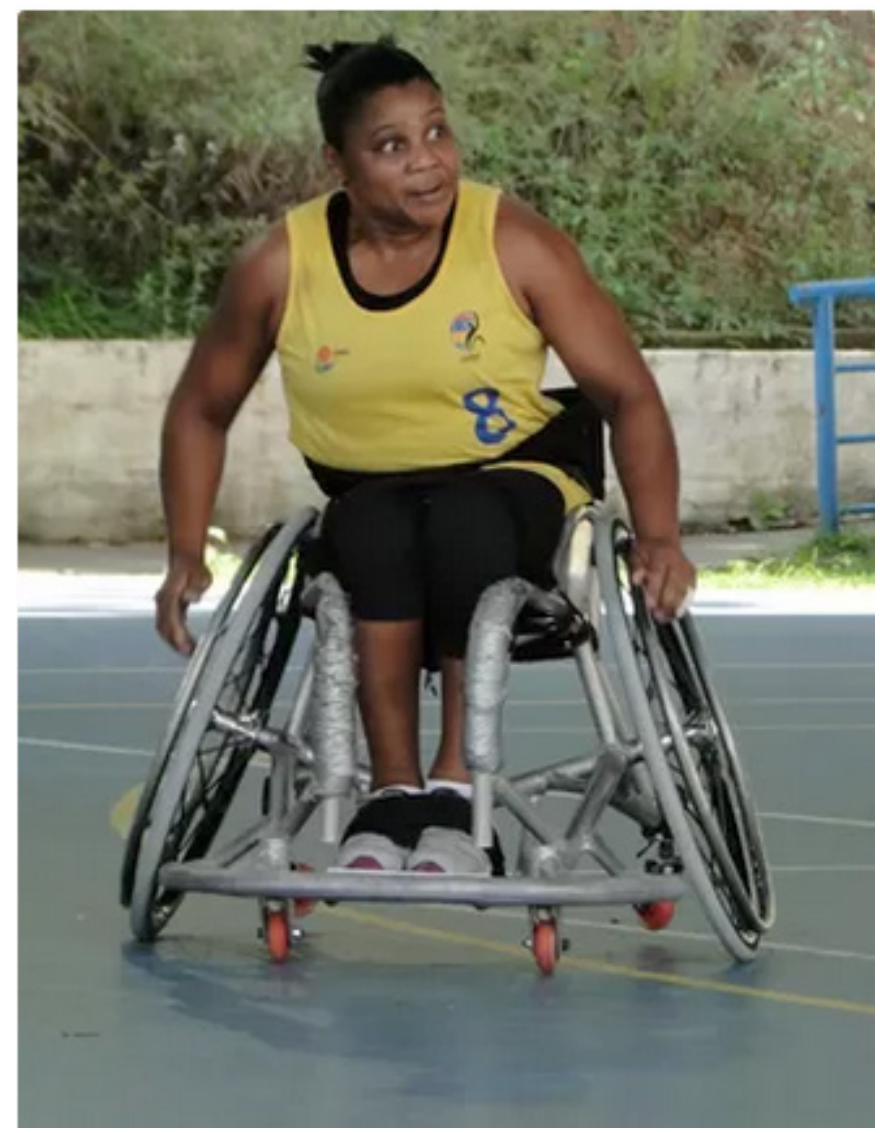

Imagem 1: Aos 45 anos, Rosália Ramos é destaque do Brasil no Parapan (Foto: Helena Rebello).

Fonte: Globoesporte.com, 07/08/2015

Após a conquista da medalha de ouro no paraciclismo de estrada pelo atleta brasileiro Lauro Chamam, o título, que se supunha buscar dar visibilidade, mostrou-se, de certa forma, apelativo: “"Perna mecânica' e trauma familiar: ouro coroa volta por cima de brasileiro" (GUERRA, 08/08/2015a). O atleta Lauro Chamam é representado como uma pessoa corajosa que superou suas limitações e as dificuldades da vida. Moura (1993) assevera que os atletas: "São de certa forma vistos publicamente como elementos não humanos: um pela sua história e seu modo precário de vida, como elemento sub-humano, o outro pelo inverso da mesma moeda - da deficiência - como um super-humano" (p. 46). Além de narrar uma tragédia familiar na vida do atleta, a notícia destaca a tatuagem de "perna mecânica" (imagem 2), através de uma fotografia abordando sua deficiência, o que caracteriza a relevância que se atribui para essa informação. 


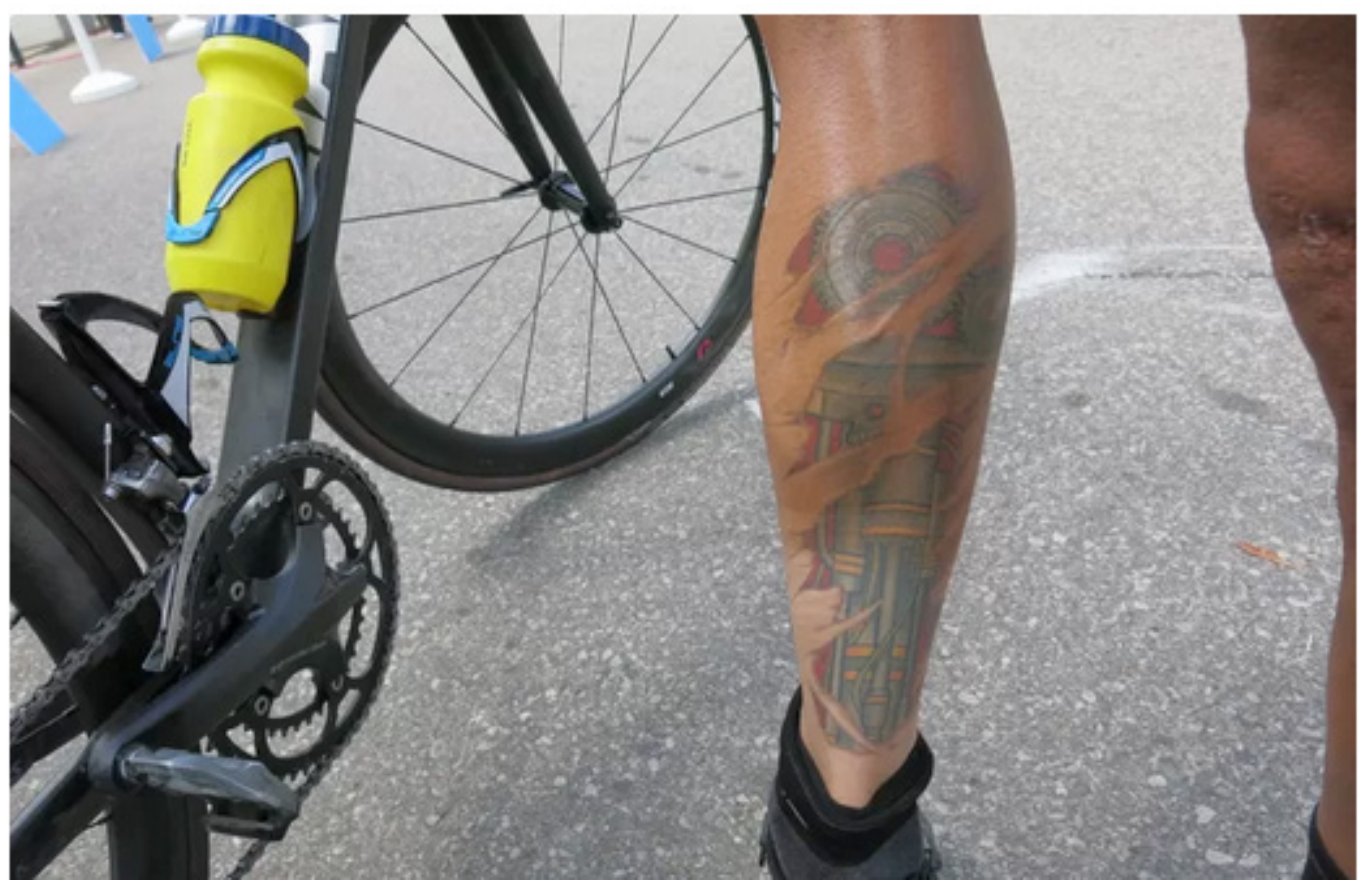

Imagem 2: Lauro Chaman exibe tatuagem de perna mecânica (Foto: Marcos Guerra) Fonte: Globoesporte.com, 08/08/2015.

A notícia intitulada "O peso da falta de apoio: halterofilista vira símbolo do paradesporto no Haiti" (REBELLO, 09/08/2015a), aborda a problemática da falta de incentivo ao paradesporto, utilizando-se do estereótipo do super-heroi, termo aludido por Sheel e Duncan (1999). O super-heroi da notícia é representado pela atleta Nephtalie Jean-Louis que, representando uma nação, sucumbe frente às adversidades. Em trecho da notícia, o técnico Coissi Dogbe que acompanhou a atleta haitiana afirma: "Ela pratica porque gosta, para fazer parte da sociedade", o que retrata um dos princípios de origem do paradesporto, a reabilitação social (VARELA, 1989).

A atuação do atleta vice-campeão no tiro com arco é abordada como ato heroico, e alude que ele serve de inspiração para as pessoas. Tal opinião estabelece-se no título da matéria explorando a condição de pessoa com deficiência, “Arqueiro sem braços, americano tenta inspirar as pessoas: 'Tudo é possível". Além disso, o entendimento é reforçado pelo uso de termos no texto referindo-se ao atleta como: "astro paralímpico", "famoso", “criança especial”, "arqueiro inspirador” (GUERRA, 10/08/2015b). Percebe-se mais uma vez a preocupação em destacar a deficiência do atleta, e a repetição da expressão "sem braços", como é possível identificar no seguinte trecho:

Sem explicação médica, ele nasceu sem braços, fato muito raro - pesquisas estimam que 1 a cada 350 mil crianças nasça assim. Os pais biológicos se assustaram com ideia de criar uma criança especial, e Matt foi adotado com apenas quatro meses de idade por Leon e Jean Stutzman. O casal deu liberdade para o garoto sem braços crescer livremente pela fazenda da família e aprender a lidar com a vida sem braços e sem tratamentos especiais. 
SANTOS; MAZO E CARMONA - Atletas brasileiros nos jogos Parapan-Americanos de 2015: Uma abordagem apelativa do site globoesporte.com

Outra história de superação foi noticiada (REBELLO, 11/08/2015b) referindo o atleta paralímpico da seleção brasileira de basquetebol em cadeira de rodas e impactando o leitor com o título: "Empurrado em carrinho de bebê até os 13, Dwan muda de vida com basquete". Como símbolo da luta da pessoa com deficiência com poucas condições financeiras, a representação cultural atribuída ao atleta paralímpico oscila da posição de "coitado" a "herói”. Alguns termos utilizados na notícia caracterizam essa intenção: "humilde”, “o menino”, “caçula”, "uma das maiores promessas do país na modalidade”.

“Da altura da mala, Montanha brinca após bronze: “Excesso de bagagem”” (REBELLO, 12/08/2015C) é o título da notícia que revela uma nuança de chiste ao relacionar o volume de bagagem do atleta em relação ao seu tamanho, aspecto associado à sua deficiência. Não apenas o título, mas também a fotografia (imagem 3) refere-se ao tamanho da mala do atleta e o texto, que usa uma linguagem com "estilo descontraído", que reforça estereótipos para representar a conquista de medalhas por quatro brasileiros no halterofilismo. No decorrer do texto é repetitiva a informação sobre a deficiência do atleta: "foi um dos três exemplos do Brasil no Parapan do sucesso dos anões no halterofilismo. Dos quatro atletas com nanismo que representaram o país na competição, apenas o caçula, Gustavo Tavares, não conquistou medalha". A matéria, ainda, abona o enfoque de comparação do tamanho da mala argumentando que o próprio atleta usou tal abordagem: "se despede de Toronto nesta quarta-feira aliviado pela sensação de ter subido no pódio e fazendo piada sobre a própria bagagem antes de embarcar de volta ao Brasil”. É possível que este enfoque se estabeleça como uma tentativa de justificar a atitude do jornalismo especializado ao transmitir estigmas e estereótipos dos atletas.

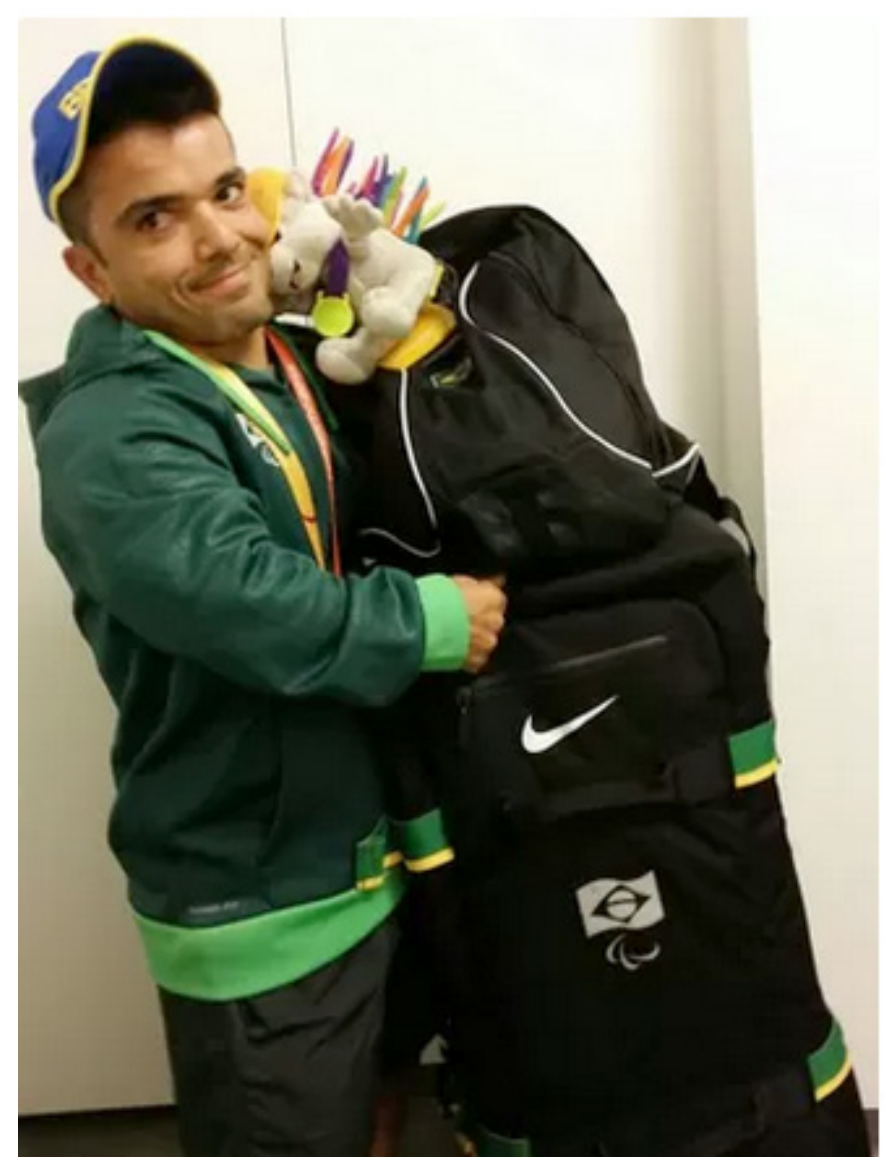

Imagem 3: Luciano Montanha com sua mala levada ao Parapan de Toronto (Foto: Arquivo Pessoal).

Fonte: Globoesporte.com, 12/08/2015. 
Segundo Lage (2001), o papel do jornalismo esportivo é transmitir a informação com credibilidade. "É erro crasso exagerar o papel do jornalismo como ditador da opinião pública, mas tornou-se axioma o oficio - algo que nós, jornalistas, considerados auto-evidente - a convicção de que ele contribui positivamente quando exercido de maneira correta" (LAGE, 2001, p. 19).

A notícia intitulada "Do salto sobre cama à prata: brasileiro voa alto com apenas uma perna" (REBELLO; GUERRA, 13/08/2015b) retrata o atleta como "herói” ao explorar sua deficiência física. "Mesmo com apenas uma perna, ele venceu adversários com duas pernas para conquistar a prata no salto em altura". Ao interpretar a notícia percebe-se que a intenção é, sobretudo, impressionar o leitor com a informação sobre a deficiência do atleta em relação ao seu desempenho, distinguindo-o como "corajoso" ao destacar sua limitação em relação aos demais competidores da modalidade. Com relação a esta construção identitária do atleta com deficiência, Hilgemberg (2014b) identificou a existência um discurso de que as pessoas com deficiência precisam inspirar as demais pessoas com histórias de superação para poderem se ajustar a sociedade. Dessa forma, ocorre o reconhecimento destas pessoas como úteis a sociedade, pois são "inspiradoras" e "corajosas".

A história de vida da atleta paralímpica Macarena Cabrillan foi propagada pelo site, com o título "Paraplégica após tentativa de suicídio, chilena é salva pelo tênis em cadeira de rodas" (REBELLO, 14/08/2015d). Constata-se a intenção em suscitar comoção ao leitor, dando ênfase à superação da atleta frente à tragédia vivenciada. Com o uso de alguns termos ao longo do texto, como: “cabeça baixa”, "frustação”, “derrotas”, "fatídico”, “tragédia”, percebe-se que a atleta paralímpica do tênis em cadeira de rodas é retratada como "vítima”, e até mesmo "coitada". A notícia também informa sobre a conquista do pódio dos atletas na modalidade, porém esta é anotada de forma sucinta, indicando uma informação secundária. Desse modo, pode-se identificar que o foco da matéria é a representação da personagem como um símbolo de superação, carecendo o reconhecimento como atleta paralímpica, ou seja, atleta de alto rendimento esportivo. Tal ocorrência também é vista no estudo de Bajaña, Alonso e Corredor (2010), no qual os autores descrevem a história de vida de uma atleta colombiana com deficiência, Naiver Ome, da natação, destacando os sacrifícios, a força e a paciência como fatores determinantes para que a atleta superasse as adversidades, prosseguisse na carreira e tivesse sucesso no esporte.

Muitas vezes, a prática esportiva é alocada em segundo plano nas notícias. No caso da matéria “Cego por tiro acidental, carioca dá a volta por cima com conquistas no judô" (DILASCIO, 15/08/2015), caracteriza-se pela ideia de superação do atleta paralímpico. Consta no decorrer do texto: "mesmo sem um dos principais sentidos, o carioca enxergou um novo horizonte no esporte adaptado". Conforme Calvo (2001) “nessas questões do corpo ‘perfeito' mediatizado, as pessoas com algum tipo de deficiência encontram-se à margem daquilo que é aceite socialmente" (p. 22).

Carmona, Pereira e Mazo (2015), em um estudo de caso, buscaram narrar o percurso histórico de Rosângela Dalcin, atleta brasileira do tênis de mesa adaptado. Observou-se que o material acessado para este estudo muitas vezes enfocou mais a tragédia pessoal da atleta do que sua história esportiva.

Além disso, informações sobre o Tênis de Mesa Adaptado raramente eram mencionadas nas reportagens. 
O esporte adaptado e o esporte paralímpico são representados como uma forma de dar sentido à vida da pessoa com deficiência, ou seja, uma maneira de se sentir vivo. As notícias revelaram que o esporte representado como reabilitação é mais relevante do que a condição de atleta medalhista e a própria modalidade esportiva. O atleta mais uma vez é sinônimo de herói, indivíduo corajoso que supera seus limites e adversidades da vida. Os veículos de comunicação, muitas vezes, ignoram que o esporte de alto rendimento praticado por atletas com deficiência, envolve treinamento específico e exaustivo, assim como o esporte de alto rendimento realizado pelos atletas que não tem deficiência.

\section{Considerações Finais}

Através da análise da cobertura jornalística do Globoesporte.com/parapan nos Jogos Parapan-Americanos Toronto 2015 por meio da abordagem apelativa, percebe-se que a visibilidade conferida aos atletas visa comover o leitor ao disseminar representações culturais estigmatizadas. Para isso, utilizou-se de terminologias que representam o atleta como "vítima" de sua deficiência, destacando as limitações físicas, e, da mesma forma, como "herói”, tornando-se exemplo de vida e coragem. A aceitação no meio social, da pessoa com deficiência, estabelece-se na cobertura jornalística em questão, a partir dos feitos surpreendentes para se encaixar e se tornar útil à sociedade.

O conteúdo disponibilizado pela referida mídia esportiva mostra atletas de corpos imperfeitos que despertam olhar de pesar dos leitores, através de histórias dramáticas, que se transformam em narrativas de superação. Percebeu-se a relevância em narrar a fatídica história de origem da imperfeição do corpo, que é marcada pelo encontro com o esporte, como forma de reinserção social.

Tendo em vista tal representação, por vezes, estereotipada, o estudo repensa o papel do jornalismo esportivo do veículo de comunicação na representação cultural dos atletas com deficiência. A visibilidade conferida aos Jogos Parapan-Americanos necessita ser reconfigurada, de forma a tornar o esporte reconhecido através de suas diferentes modalidades esportivas, métodos de treinamento, desempenho esportivo dos atletas e histórico do evento esportivo, entre outros fatores de interesse social.

Apesar do número pequeno de matérias selecionadas para este estudo, nota-se que o referido site esportivo precisa repensar a finalidade das mensagens veiculadas, de modo a fazer a escolha adequada dos termos, abordagem e imagens na veiculação da informação. O jornalismo reproduz mais do que informações, produz sentido em suas mensagens, disseminando ideias que podem transformar posturas preconceituosas transmitidas culturalmente, em reconhecimento às diferentes modalidades esportivas e estímulo a formação de atletas com deficiência. 


\section{Referências}

ALCOBA, L. A. El periodismo desportivo en la sociedade moderna. Madrid: El Autor, 1980.

ALEXANDRE, M. O papel da mídia na difusão das representações sociais. Comun, Rio de Janeiro, v. 6, n. 17, jul./dez.p. 111-125, 2001.

BAJAÑA, R. D.; ALONSO, C. T.; CORREDOR, N. N. Historia de vida de una deportista paralímpica colombiana. Educación Física y Deporte, Medellín, v. 29, n. 1, p. 95-101, 2010.

BARBEIRO, H.; RANGEL, P. Manual do jornalismo esportivo. São Paulo: Contexto, 2006.

BRAZUNA, R. M.; CASTRO M. E. A trajetória do atleta portador de deficiência física no esporte adaptado de rendimento. Uma revisão da literatura. Motriz, Rio Claro, v. 7, n.2, p. 115-123, jul./dez. 2001.

CALVO, A. P. Desporto para deficientes e media. Dissertação (Mestrado em Ciências do Desporto) - Faculdade de Ciências do Desporto da Universidade do Porto, UP, Porto, 2001.

CAMARGO, V. R. T. O pensamento de Antonio Alcoba e sua importância na Trajetória dos Estudos e Pesquisas sobre o Jornalismo Esportivo no Brasil. In: V Encontro de Núcleos de Pesquisa da Intercom, XVIII Congresso Brasileiro de Ciências da Comunicação. Anais... Rio de Janeiro, 2005.

CARMONA, E. K.; PEREIRA, E. L; MAZO, J. Z. Tênis de mesa adaptado: pelos caminhos do esporte em uma cadeira de rodas. Biomotriz, Cruz Alta, v. 9, n. 1, p. 38-53, 2015.

CASTRO, L. Comunicación deficiente, deporte deficiente. Chaqui: Revista Latinoamericana de Comunicación. Quito: Cisepal, n. 51, p. 56-57, jul. 1995.

CURADO, O. A notícia na TV - o dia-a-dia de quem faz Telejornalismo. São Paulo: Alegro, 2002.

DILASCIO, F. Cego por tiro acidental, carioca dá a volta por cima com conquistas no judô. Globoesporte. com, 15 ago. 2015. Disponível em: <http://globoesporte.globo.com/parapan/noticia/2015/08/cego-por-tiro-acidental-carioca-da-volta-por-cima-com-conquistas-no-judo.html>

ERBOLATO, M. L. Jornalismo especializado: emissão de textos no jornalismo impresso. São Paulo: Atlas, 1981.

GUERRA, M. "Perna mecânica” e trauma familiar: ouro coroa volta por cima de brasileiro. Globoesporte. com, 08 ago. 2015a. Disponível em: <http://globoesporte.globo.com/parapan/noticia/2015/08/perna-mecanica-e-trauma-familiar-ouro-coroa-volta-por-cima-de-brasileiro.html> 
GUERRA, M. Arqueiro sem braços, americano tenta inspirar as pessoas: “Tudo é possível”. Globoesporte.com, 10 ago. 2015b. Disponível em: <http://globoesporte.globo.com/parapan/noticia/2015/08/arqueiro-sem-bracos-americano-busca-inspirar-pessoas-tudo-e-possivel.html>

HILGEMBERG, T.; NOVAIS, R. A Antiguidade ainda é um posto? Os momentos de vitória nos Paraolímpicos de Pequim. In: XXXII CONGRESSO BRASILEIRO DE CIÊNCIAS DA COMUNICAÇÃO, 32, 2009, Curitiba. Anais... São Paulo: Intercom, 2009.

HILGEMBERG, T. Do Coitadinho ao Super-heroi Representação social dos atletas paraolímpicos na mídia brasileira e portuguesa. Ciberlegenda, Niterói, v. 1, p. 48-58, 2014 b.

HILGEMBERG, T. Primeiro o Esporte, depois a deficiência: análise da cobertura midiática dos Jogos Paralímpicos de 2012. In: XXXVII CONGRESSO BRASILEIRO DE CIÊNCIAS DA COMUNICAÇÃO, 37, 2014, Foz do Iguaçu. Anais... São Paulo: Intercom, 2014a.

KOSSOY, B. Realidades e ficções na trama fotográfica. Cotia: Ateliê Editorial, 1999.

LAGE, N. A reportagem: teoria e técnica de entrevista e pesquisa jornalística. Rio de Janeiro: Record, 2001.

MARQUES. C. A. A imagem da alteridade da mídia. Tese (Doutorado em Doutorado em Comunicação e Cultura) - Escola de Comunicação, UFRJ, Rio de Janeiro, 2001.

MOURA, L. C. M. A deficiência nossa de cada dia: de coitadinho a super-herói. São Paulo: Iglu, 1993.

REBELLO, H. Da altura da mala, Montanha brinca após bronze: “Excesso de bagagem”. Globoesporte. com, 12 ago. 2015c. Disponível em: <http://globoesporte.globo.com/parapan/noticia/2015/08/da-altura-da-mala-montanha-brinca-apos-bronze-excesso-de-bagagem.html>

REBELLO, H. Empurrado em carrinho de bebê até os 13, Dwan muda de vida com basquete. Globoesporte.com, 11 ago. 2015b. Disponível em: <http://globoesporte.globo.com/parapan/noticia/2015/08/empurrado-em-carrinho-de-bebe-ate-os-13-dwan-muda-de-vida-com-basquete.html>

REBELLO, H. O peso da falta de apoio: halterofilista vira símbolo do paradesporto no Haiti. Globoesporte.com, 09 ago. 2015a. Disponível em: <http://globoesporte.globo.com/parapan/noticia/2015/08/o-peso-da-falta-de-apoio-halterofilista-vira-simbolo-do-paradesporto-no-haiti.html> 
REBELLO, H. Paraplégica após tentativa de suicídio, chilena é salva pelo tênis em cadeira de rodas. Globoesporte.com, 14 ago. 2015d. Disponível em: <http:/globoesporte.globo.com/parapan/noticia/2015/08/ paraplegica-apos-tentativa-de-suicidio-chilena-e-salva-pelo-tenis-em-cadeira.html>

REBELLO, H.; GUERRA, M. Do salto sobre cama à prata: brasileiro voa alto com apenas uma perna. Globoesporte.com, 13 ago. 2015b. Disponível em: <http:/globoesporte.globo.com/parapan/noticia/2015/08/ do-salto-sobre-cama-prata-brasileiro-voa-alto-com-apenas-uma-perna.html>

REBELLO, H.; GUERRA, M. Vovó? Aos 45 anos, Rosália coloca novatas no bolso e esbanja boa forma. Globoesporte.com, 07 ago. 2015a. Disponível em: <http:/globoesporte.globo.com/parapan/noticia/2015/08/ vovo-aos-45-anos-rosalia-coloca-novatas-no-bolso-e-esbanja-boa-forma.html>

SANTOS, K. J. G. M. Jogos Parapan-Americanos de Toronto/Canadá: representações veiculadas através da cobertura jornalística. Monografia (Especialização em Jornalismo Esportivo) - Faculdade de Biblioteconomia e Comunicação, UFRGS, Porto Alegre, 2015.

SEIXAS, L. Teorias de jornalismo para gêneros jornalísticos. Galaxia, São Paulo, n. 25, p. 165-179, 2013. TRAQUINA, N. Teorias do Jornalismo - Porque as notícias são como são. $2^{\text {a }}$ ed. Florianópolis: Insular, 2005.

VARELA, A. Desporto para as pessoas com deficiência. Revista Educação Especial e Reabilitação, Lisboa, v. 1, n. 5/6, jun. 1989 . 